Aim of the study: Efficacy of stereotactic radiosurgery (SRS) in the treatment in cerebral AVM's, mennigiomas, metastases, acoustic neuromas and recurrent anaplastic gliomas is well documented. The object of this work was the analysis of the results of the treatment of AVM and selected cerebral lesions with linear accelerator-based stereotactic radiosurgery.

Material and methods: The lesions included: 12 AVMs, 2 cavernomas, 27 meningiomas, 16 metastases, 5 acoustic neuromas, 16 gliomas in 78 patients. A mean radiation dose of $16 \mathrm{~Gy}$ was delivered to the tumour or AVM margin and 12Gy to the tumours located in a ponto-cerebellar angle. Follow-up was 18 months.

Results: Control of tumour growth or AVM was achieved in all cases after 6 months and radiological regression was observed in 20 cases after 12 months. The best results were noted in AVM's, meningiomas and neuromas. There were no new permanent deficits nor complications after radiosurgery requiring medicamentation.

Conclusions: Organization of SRS in Oncological Center in Bydgoszcz involv ing close co-operation of radiotherapist, neurosurgeon and physicist in the process of qualification and treatment planning is based on the best global standards. Preliminary results of treatment are consistent with the literature data. A longer follow-up is required to determine the long term efficacy and the toxicity of this treatment in our institution.

Key words: stereoradiosurgery, AVM's, meningiomas, metastases, acoustic schwanomas.

\section{Preliminary results of linac-based radiosurgery in arteriovenous malformations and cerebral tumours in the Oncology Centre in Bydgoszcz}

\author{
Paweł Sokal ${ }^{1}$, Andrzej Lebioda ${ }^{2}$, Maciej Harat ${ }^{2}$, Jacek Furtak ${ }^{1}$, Monika Grzela ${ }^{2}$, \\ Renata Kabacińska², Roman Makarewicz², Piotr Zieliński', Wiesława \\ Windorbska
}

1Department of Neurosurgery, Military Clinical Hospital, Bydgoszcz, Poland 2Franciszek Lukaszczyk Oncology Center, Bydgoszcz, Poland

\section{Introduction}

Stereotactic radiosurgery (SRS) is a method of treatment of intracranial tumours and arteriovenous malformations (AVMs) or functional disorders with a precisely delivered, single dose of radiation, limited to the localized area of the lesion $[1,2]$. Radiosurgery may be performed using the Gamma Knife ${ }^{\circledR}$ (a device emitting gamma rays from cobalt sources); a linear accelerator (LINAC) - an accelerator of photon beams modified by a microleaf collimator; and using a beam of protons - the proton beam system [3]. During the treatment the head is mounted in a stereotactic frame. A facial mask is applied when it is necessary to repeat irradiation in stereotactic radiotherapy. The treatment can be conducted after planning of the irradiation on the basis of detailed images of MRI (magnetic resonance imaging) of the head which depicts pathological changes. CT (computed tomography) in the stereotactic frame is used for MRICT image fusion [1]. In centres of excellence the team conducting SRS consists of a radiotherapist, neurosurgeon, physicist and nurse [2]. The most common indications for the radiosurgical treatment are small or medium-sized intracranial tumours such as meningiomas, brain metastases, auditory nerve schwannomas and AVMs with a nidus of diameter less than $3 \mathrm{~cm}$, pituitary adenomas, and recurrent gliomas [1-10]. The aim of this study is to make a preliminary assessment of treatment effects of intracerebral AVMs and tumours using SRS in the Oncology Centre in Bydgoszcz.

\section{Material and methods}

From January 2009 to September 2010 in the Department of Radiation Oncology, in close cooperation with the Department of Neurosurgery in the Military Hospital in Bydgoszcz 78 patients with vascular malformations and intracerebral tumours were treated with SRS using the isocentric accelerator Varian with linear energy of photon beam 6 MEV collimated by a multi-microleaf collimator of the BrainLab planning system. For each patient, preoperative MRI and $\mathrm{CT}$ of the head was performed, and then distribution of the irradiation dose was planned by the team consisting of a radiotherapist, neurosurgeon and physicist. Patients were immobilized during SRS in the stereotactic frame (29 cases) or in a facial mask (49 cases). SRS was performed on 47 women and 31 men, who, due to concomitant diseases and the lack of consent for surgical intervention, were not qualified for surgery. These were people with intracranial changes of size not exceeding $3.5 \mathrm{~cm}$ in diameter and location which allowed for sparing from radiation the brain stem, nerves, optic chiasm, and eyeballs. The targeted lesions were 12 AVMs and 2 cases of cavernous mal- 
Table 1. Results of radiological assessment of MRI images at 12 months after the treatment of intracranial lesions

\begin{tabular}{|lcccc|}
\hline Type of target & Pollow-up & $\begin{array}{c}\text { w/o } \\
\text { percentage } \\
\text { of cases } \\
\text { of radiological } \\
\text { regression } \\
\text { after } 12 \text { months }\end{array}$ & $\begin{array}{c}\text { Number and } \\
\text { of radiological } \\
\text { stability } \\
\text { of cases }\end{array}$ \\
\hline number of cases & 78 & 19 & $20(25 \%)$ & $36(46 \%)$ \\
\hline AVM & 12 & 2 & $7(53 \%)$ & $5(41 \%)$ \\
\hline cavernoma & 2 & 0 & 0 & $1(50 \%)$ \\
\hline meningiomas & 27 & 2 & $6(22 \%)$ & $21(77 \%)$ \\
\hline $\begin{array}{l}\text { acoustic } \\
\text { schwannomas }\end{array}$ & 5 & 0 & $3(60 \%)$ & $2(40 \%)$ \\
\hline metastases & 16 & 9 & $1(6 \%)$ & $4(25 \%)$ \\
\hline glioma A3 & 16 & 6 & $3(18 \%)$ & $2(12.5 \%)$ \\
\hline
\end{tabular}

AVM - artiovenous malformation

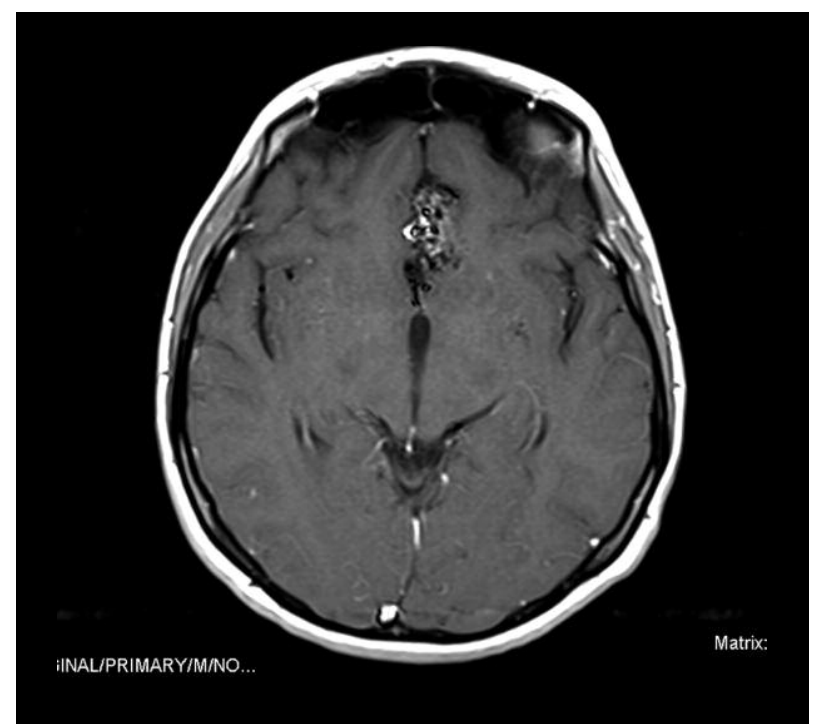

prior to SRS formations, 27 meningiomas, 5 auditory nerve schwannomas, 16 anaplastic gliomas and 16 brain metastases. In 3 patients two metastatic brain lesions were treated. The average irradiation dose to the periphery of the tumour or malformation was 16 Gy and 12 Gy for tumours located in the pontocerebellar angle with border isodose of $90 \%$. The follow-up period ranged from 6 to 18 months.

\section{Results}

Results of radiological assessment of MRI images at 12 months after the treatment of intracranial lesions are shown in Table 1. Control of tumour growth or of AVM size was achieved in all cases after 6 months. Radiographic regressions (defined as decrease in size and/or in contrast enhancement) were observed after 12 months in 53\% of AVMs [7/12], 22\% of meningiomas [6/27], $6 \%$ of metastases [1/16] and $18 \%$ of anaplastic gliomas [3/16]. There were no complications after radiosurgery requiring pharmacological treatment. One patient had haemorrhage from a cavernous angioma locat-

Fig. 1A. Effect of SRS of interhemispheric frontal AVM after 12 months (regression of contrast enhancement)

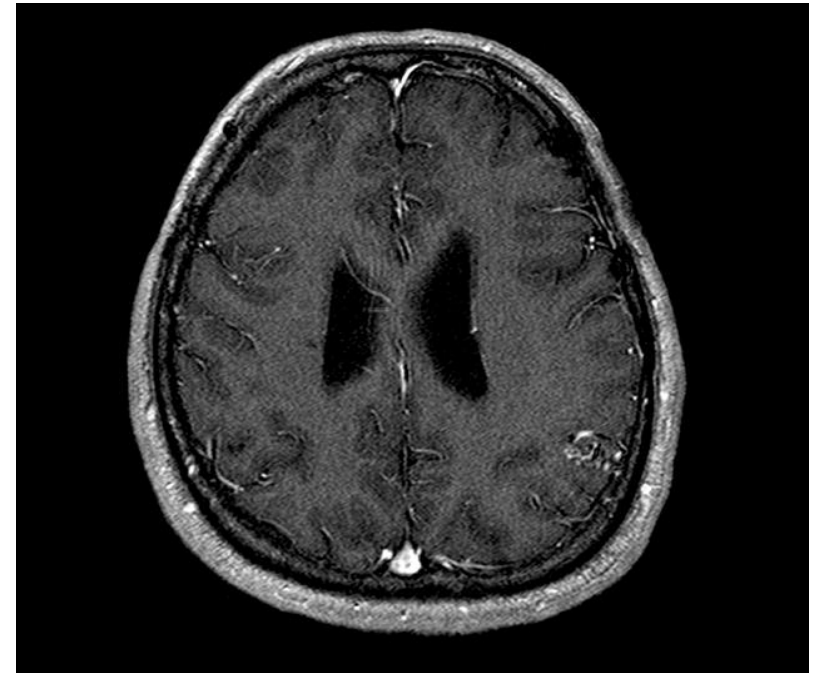

prior to SRS

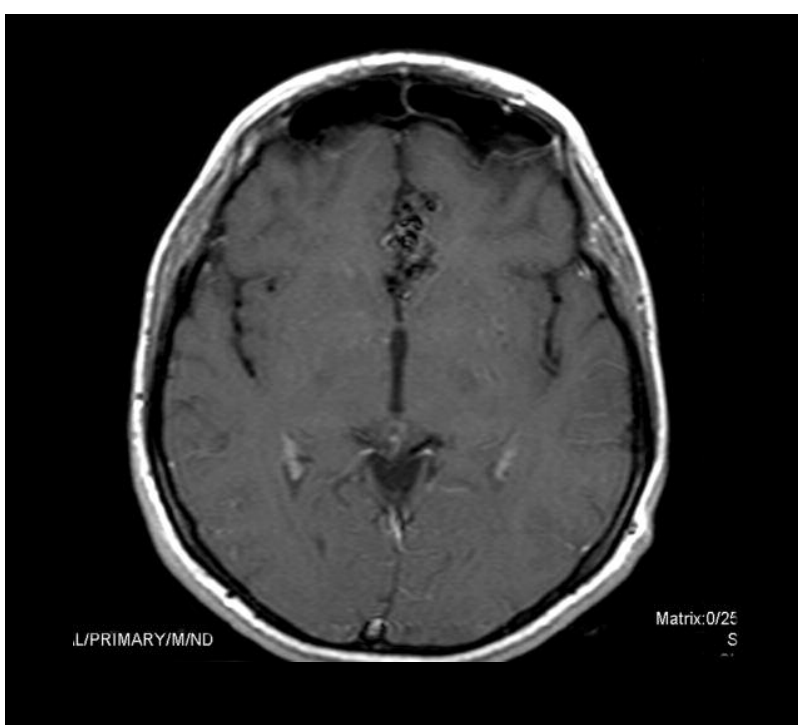

after 12 months

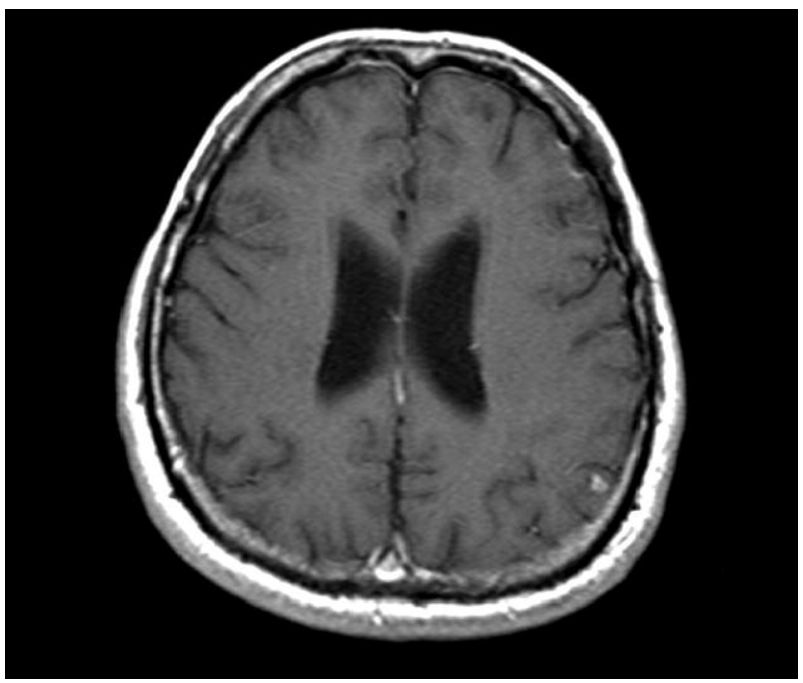

after 18 months

Fig. 1B. Effect of SRS of left occipital AVM after 18 months (regression of size) 


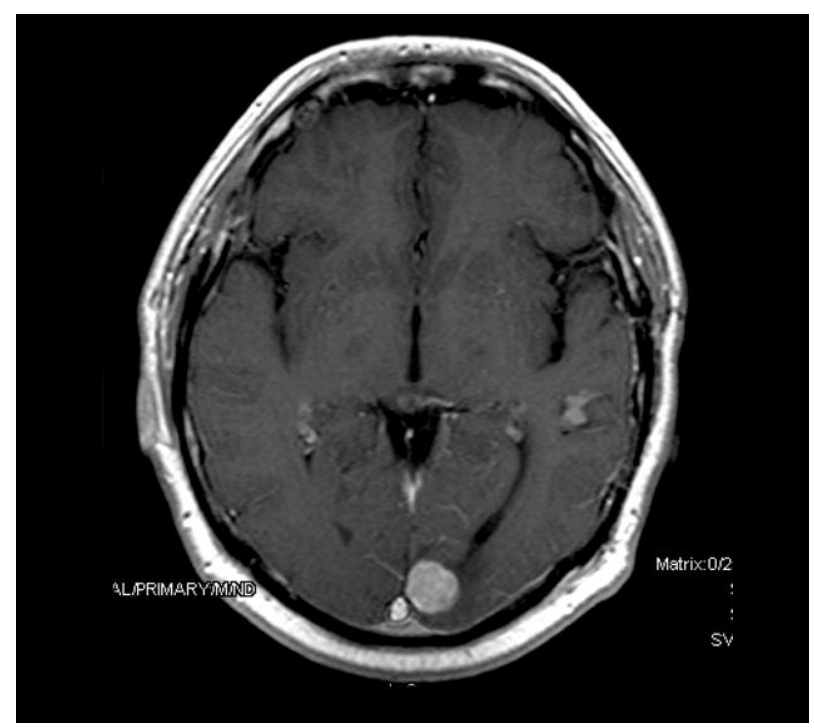

before

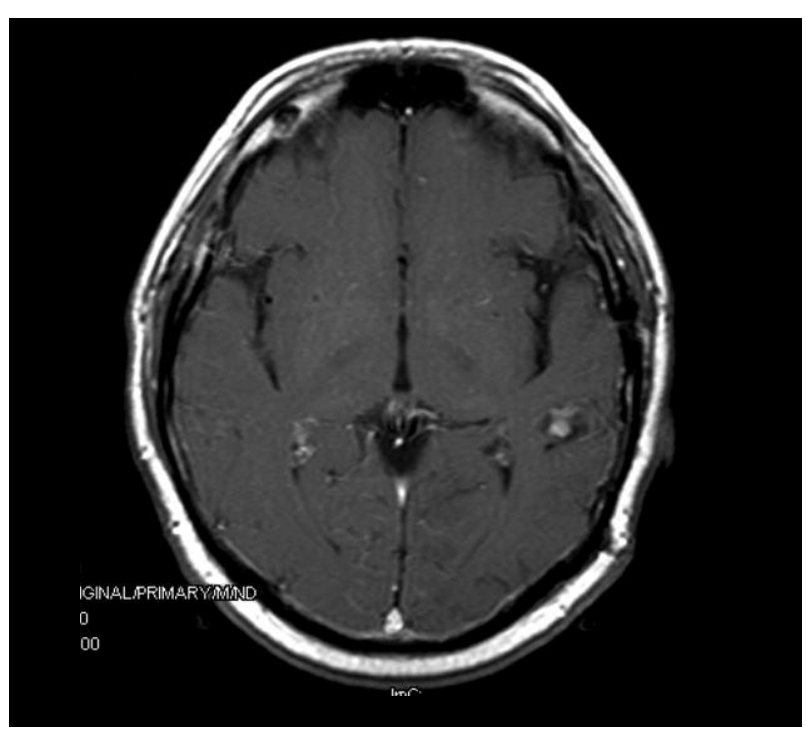

after

Fig. 2. Effect of SRS of metastasis of renal carcinoma in left occipital lobe after 6 months
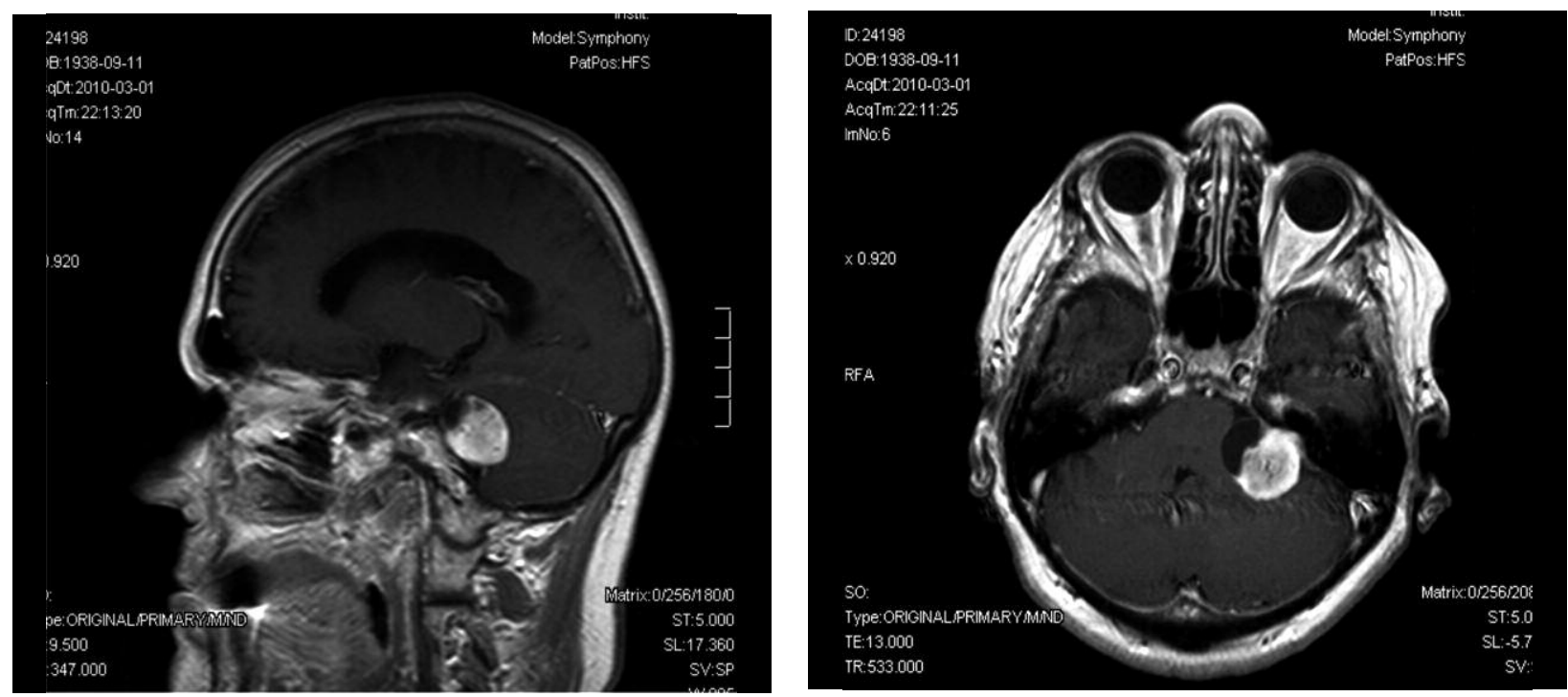

before treatment
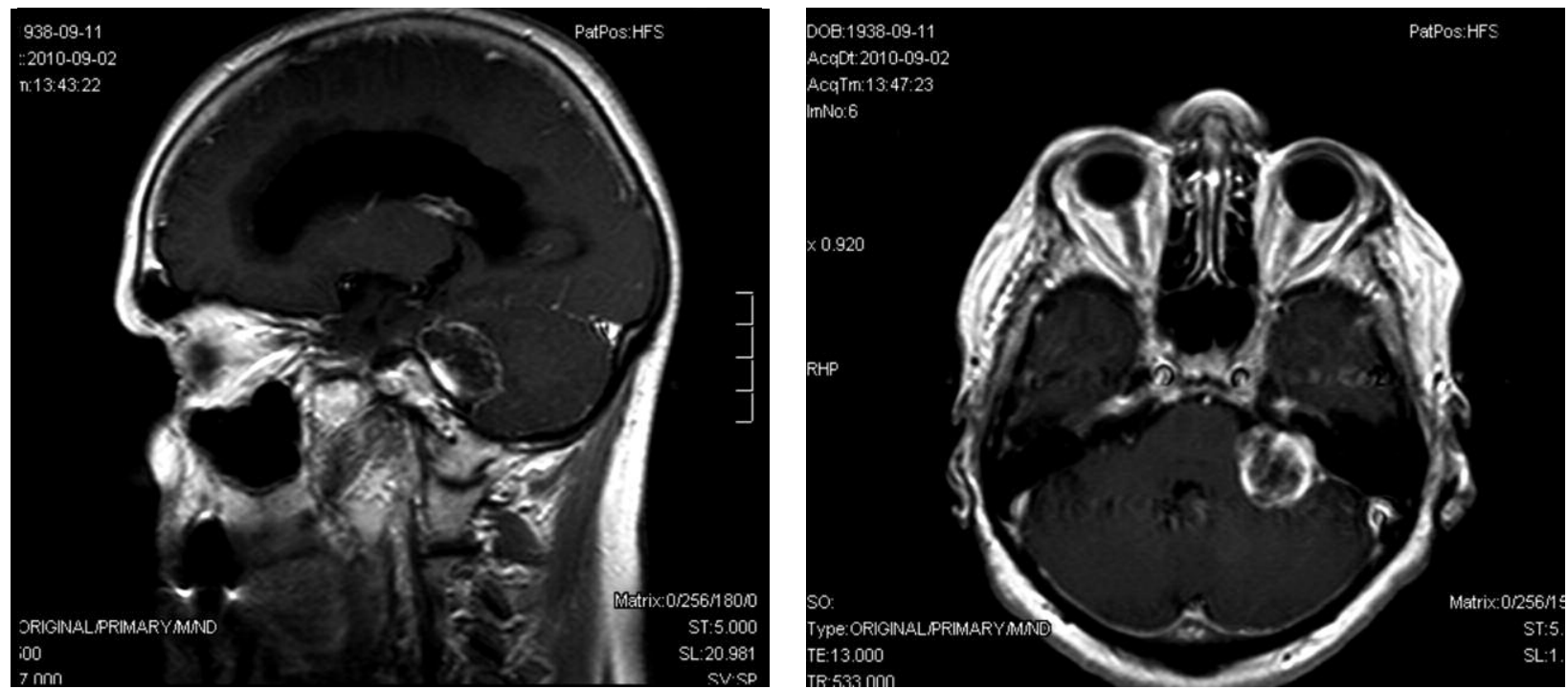

after 6 months

Fig. 3. Effect of SRS of schwannoma located in left cerebellopontine angle - reduction of contrast enhancement after 6 months 


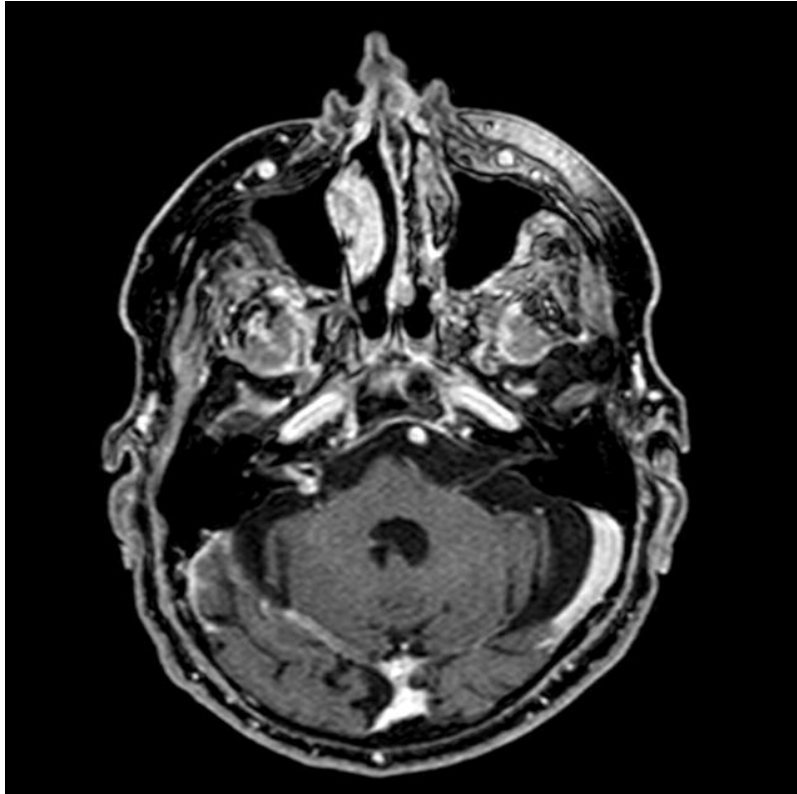

before

after

Fig. 4. Effect of SRS of schwannoma located in right cerebellopontine angle - reduction of size of tumour after 18 months

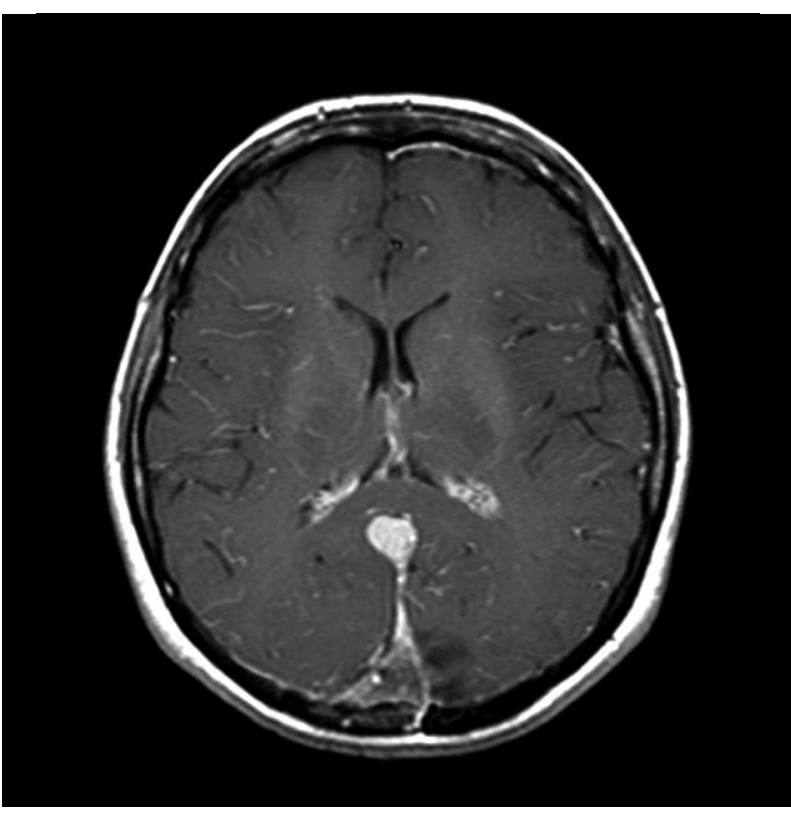

before

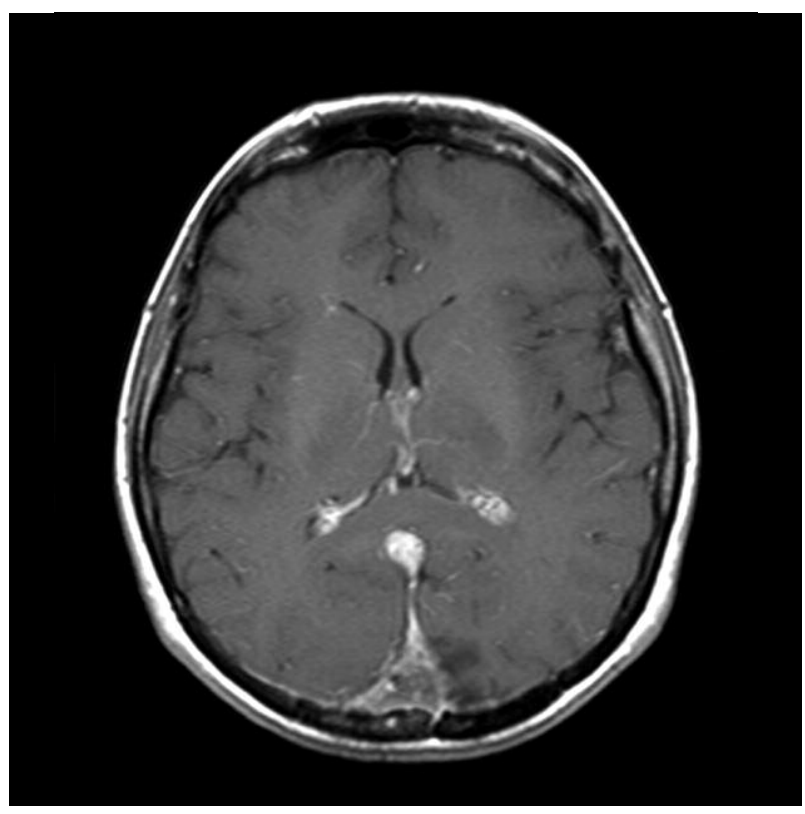

after

Fig. 5. Effect of SRS of falcine meningioma after 18 months

ed in the left thalamus eight months after surgery, which required anti-oedematous treatment because of worsening of right-side hemiparesis. In the group of five schwannomas, there was no postoperative deterioration of facial nerve function. Radiographic progressions after 12 months were noted in gliomas and metastases. The illustrations (Figures 1A,B 2-5) - show changes in selected cases of intracranial lesions treated in the Oncology Centre in Bydgoszcz.

\section{Discussion}

The main advantage of radiosurgery is its minimal invasiveness and high effectiveness reflected in inhibition of tumour growth and the obliteration of arteriovenous malformation. The important issue is short hospitalization and low complication rates pertinent in neurosurgical interventions such as bleeding, infection, and neurological deficits temporary or permanent. Radiosurgical treatment costs are lower than neurosurgical treatment costs [3-11].

Stereotactic radiosurgery is indicated in small or mediumsized AVMs located in deep brain structures, in eloquent areas, and/or those which have high surgical risk of neurological deficit or intracerebral haemorrhage, as well as those whose size does not allow for conducting complete endovascular embolization $[1,6]$. The effect of SRS is the obliteration of AVM. In our mate- 
rial in 5 cases out of 11 we observed a reduction in the size of AVM after 12 months follow-up. In one case stereotactic radiotherapy with two fractions was performed due to large size of AVM. The effectiveness of treatment of AVMs with a diameter of less than $3 \mathrm{~cm}$ is well documented and is reported in more than $90 \%$ of cases. Large AVMs have a lower effectiveness rate of radiosurgery [6]. In our centre we also performed SRS of cavernomas, which had been a source of bleeding, located in subcortical nuclei disqualified from surgical intervention. Out of two cases with cavernomas, in one we observed haemorrhage in the left thalamus 6 months after SRS. It seems that this incident was due to the natural history of the disease and increased risk of bleeding from the lesion, which had bleeding pre-treatment history [12]. For acoustic neuromas control of tumour growth is achieved in $95 \%$, preservation of hearing occurs in 60-70\%, and sparing of function of the facial and trigeminal nerve is rated above $95 \%$. Schwannomas and meningiomas exerting significant compression on the brain stem or causing hydrocephalus are not eligible for SRS [2, 13]. These tumours if they are not eligible also for neurosurgical intervention due to coexisting morbidities should be irradiated in fractions. In our material we have two such cases. The most extensive group in our material are meningiomas in different locations in patients who were not operated on because of concomitant diseases or age and due to high perioperative risk or lack of consent to neurosurgical intervention. The result is inhibition of tumour growth and regression of the lesion reflected in weaker contrast enhancement observed in MRI, which was observed in $22 \%$ of meningiomas after 12 months of follow-up. In the literature control of meningiomas is described in more than $90 \%[5,14]$.

Metastatic brain tumours are almost ideal targets for SRS - recurrent or remnants after previous surgery or radiotherapy. The conditions of suitable size of less than $3.5 \mathrm{~cm}$ in diameter and a satisfactory quality of life and controlled primary focus should be fulfilled [10]. For SRS radioresistant metastases such as kidney cancer and melanoma are also eligible [15]. SRS is usually used after previous radiotherapy - WBRT (whole brain radiotherapy) - and prolongs survival [4, 9].

In conclusion, organization of SRS involving close cooperation of the radiotherapist, neurosurgeon and physicist in the process of qualification and treatment planning is based on the best global standards. Preliminary results of treatment are consistent with the literature data. A longer follow-up is required to determine the long-term efficacy and the toxicity of this treatment in our institution.

\section{References}

1. Friedman WA. Linear accelerator radiosurgery. In: Principles and Practice of Stereotactic Radiosurgery. Chin LS, Regine WF (eds.). Springer, New York 2008; 129-40.

2. Radiosurgery Practice Guideline Initiative.Stereotactic Radiosurgery for Patients with vestibular schwannomas. Radiosurgery Practice Guideline Report \#4-06: may 2006, www.irsa.org. Available at: http://www.irsa.org/AN\%20Guideline.pdf.

3. Spych M, Fijuth J, Klonowicz M, Radek M. Techniki stereotaktyczne w radioterapii ośrodkowego układu nerwowego. Onkol Prak Klin 2007; 3: $135-9$.

4. Ayoama H, Shirato H, Nakagawa K, Tago M. Interim report of the JROSG99-1 multi-institutional randomized trial, comparing radio- surgery alone versus radiosurgery plus whole brain irradiation for 1-4 metastases. Proceedings of the 40th ASCO meeting [abstract no. 1506]. J Clin Oncol 2004; 22 (14 Supplement): 1506.

5. Deinsberger R, Tidstrand J. Linac radiosurgery as a tool in neurosurgery. Neurosurg Rev 2005; 28: 79-88.

6. Liscák R, Vladyka V, Simonová G, Urgosík D, Novotný J Jr, Janousková L, Vymazal J. Arteriovenous malformations after Leksell gamma knife radiosurgery: rate of obliteration and complications. Neurosurg 2007; 60: 1005-16.

7. Matozz CA, de Salles AAF. Mennigioma. In: Principles and Practice of Stereotactic Radiosurgery. Chin LS, Regine WF (eds.). Springer, New York 2008; 233-48.

8. Roberge D, Souhami L. High-grade gliomas. In: Principles and Practice of Stereotactic Radiosurgery. Chin LS, Regine WF (eds.). Springer, New York 2008; 207-22.

9. Sneed PK, Lamborn KR, Forstner JM, et al. Radosurgery for brain metastases: is whole radiotherapy necessary? Int I Radiat Oncol Biol Phys 1999; 43: 549-58.

10. Suh JH, Barnett GH, Regine WF. Brain metastases. In: Principles and Practice of Stereotactic Radiosurgery. Chin LS, Regine WF (eds.). Springer, New York 2008; 181-92.

11. Pollock BE, Lunsford LD, Kondziolka D, Flickinger JC, Bissonette DJ, Kelsey SF, Jannetta PJ. Outcome analysis of acoustic neuroma management: a comparison of microsurgery and stereotactic radiosurgery. Neurosurgery 1995; 36: 215-24.

12. Kondziolka D, Lunsford LD, Kestle JR. The natural history of cerebral cavernous malformations. J Neurosurg 1995; 83: 820-4.

13. Mendenhall WM, Amdur RJ, Malyapa RS, Friedman WA. Acoustic Schwannoma. In: Principles and Practice of Stereotactic Radiosurgery. Chin LS, Regine WF (eds.). Springer, New York 2008; 275-82.

14. Whittle IR, Smith C, Navoo P, Collie D. Meningiomas. Lancet 2004; 363: 1535-43.

15. Chang EL, Selek U, Hassenbusch SJ 3rd, Maor MH, Allen PK, Mahajan A, Sawaya R, Woo SY. Outcome variation among radioresistant brain metastases treated with stereotactic radiosurgery. Neurosurgery 2005; 56: 936-45.

\section{Address for correspondence}

\section{Paweł Sokal}

Department of Neurosurgery

Military Clinical Hospital

Powstańców Warszawy 5

85-681 Bydgoszcz

e-mail: psokal@wp.pl

Submitted: 28.09.2011

Accepted: $\quad 15.02 .2012$ 